\title{
Therapeutic effect of the epidermal growth factor on diabetic foot ulcer and the underlying mechanisms
}

\author{
JUANZI ZHANG $^{1}$, WENXIAN HU ${ }^{1}$, QIXIAN DIAO ${ }^{2}$, ZHAOWEI WANG $^{1}$, \\ JIN MIAO ${ }^{1},{\text { XIAO } \mathrm{CHEN}^{1} \text { and ZHIJUN XUE }}^{1}$ \\ Departments of ${ }^{1}$ Vascular Surgery and ${ }^{2}$ General Surgery, \\ The Affiliated Qingdao Hiser Hospital of Qingdao University, Qingdao, Shandong 266033, P.R. China
}

Received April 17, 2017; Accepted December 15, 2017

DOI: $10.3892 / \mathrm{etm} .2018 .7133$

\begin{abstract}
The present study aimed to explore the therapeutic effect and underlying mechanism of epidermal growth factor (EGF) on the wound healing of diabetic foot ulcers (DFU). A total of 48 rabbits with DFU were randomly divided into 2 groups, comprising the treatment and control groups. Full-thickness skin $(10 \times 10 \mathrm{~mm})$ was excised from the thigh of each rabbit. The wounds in the treatment group were treated with $100 \mathrm{mg} / \mathrm{l} \mathrm{EGF}$ once a day for 1 month. The control group received no treatment. At 20 days following treatment, new granulation tissues that formed beyond the edge of the wound were collected for subsequent analysis. Tissues from rabbits in the treatment group produced a greater number of fibroblasts, which exhibited a fibroblastic morphology when compared with those in the control group. In the treatment group, a larger number of these fibroblasts were observed as clusters, and there were numerous blood vessels when compared with the control group. The fibroblasts in the control group exhibited an irregular morphology, contained fewer organelles and the surrounding collagenous fibers were sparse. These fibroblasts also demonstrated a disordered arrangement and it was revealed that the wound healed at a slower rate compared with the treatment group. Endogenous EGF mRNA detection revealed that there was a significant difference $(\mathrm{P}<0.05)$ in the relative gray value of EGF mRNA between the treatment $(103.27 \pm 4.27)$ and control $(63.88 \pm 4.36)$ groups. In conclusion, EGF may accelerate the healing of DFU, and exogenous EGF treatment may upregulate the expression of EGF mRNA in newly generated tissues.
\end{abstract}

Correspondence to: Professor Zhijun Xue, Department of Vascular Surgery, The Affiliated Qingdao Hiser Hospital of Qingdao University, 4 Renmin Road, Qingdao, Shandong 266033, P.R. China E-mail: zhijunxuezjx@163.com

Key words: epidermal growth factor, diabetic foot, wound healing, epidermal growth factor mRNA

\section{Introduction}

Diabetic foot ulcer (DFU) is a disorder observed primarily in developing countries. The blood supply in the extremities of patients with diabetes is poor, thus leading to the development of DFUs (1). The wounds require a long time to heal and may be incurable; dry gangrene can also develop as a result of DFU, which may lead to amputation in severe cases (1). Diabetes associated with acquired coagulopathies, particularly those caused by vitamin K deficiency or liver disease, may lead to excessive bleeding from the DFU and delay the healing process (2). In these cases, the use of fibrin adhesives and collagen matrices to the affected area are required (3). Such wounds can be infected by various pathogens that are difficult to treat, including fungi from the genera Fusarium or Aspergillus $(4,5)$. The study of the pathogenesis of DFU has focused on poor wound healing and delayed wound healing due to dry gangrene $(6,7)$. Numerous studies have attempted to elucidate the mechanisms underlying refractory DFU and signal transduction pathways in DFU lesions; however these studies have not been successful $(8,9)$. A study suggested that offloading, debridement and moist dressing are currently used to treat DFUs with little success (9). Unsuccessful DFU treatment is caused by a rage of factors, including the varying comorbidities observed for each diabetic patient (10). Poor wound healing is considered to be associated with poor glycemic control, refractory infection, anti-inflammatory cytokines and a relative or absolute deficiency of corresponding cytokine receptors, and vascular lesion (11). Refractory DFU lesions primarily form due to decreased expression levels of epidermal growth factor (EGF) and its receptor in DFU lesions (12). It has been demonstrated that applying active EGF to the DFU lesion may promote wound healing $(13,14)$. EGF may also promote the proliferation of gliocytes and fibroblasts, neo-epidermal thickening, peripheral nerve regeneration, as well as mediate the proliferation, migration and differentiation of gliocytes and fibroblasts (15). Previous studies have demonstrated that EGF stimulates protein synthesis by modulating the replication and signal transduction of epidermal cell DNA and RNA $(16,17)$. Previous studies investigated the repair function of the EGF receptor in the colonic mucosa of patients with ulcerative colitis (18-21). The authors demonstrated that EGF was involved in repairing inflamed mucous membranes 
in these patients. On the basis of these previous studies, and in order to aid the development of novel pharmaceutical devices based on nanotechnology for the treatment of refractory or non-healing DFU, the present study attempted to elucidate the mechanism underlying the therapeutic effect of EGF on DFU.

\section{Materials and methods}

Animals. A total of 65 healthy New Zealand white rabbits (age, 2 years old; male to female, 1:1; weight, 2.5-3.0 kg) were provided by the Jiaxiang Xian Yongwang Rabbit Sales Center (Jining, China). All the rabbits were conventionally raised with natural light, laminar circulation filter air, an indoor temperature of $25 \pm 1^{\circ} \mathrm{C}$ and the humidity at $40 \pm 5 \%$ (22-24). All animals had free access to food and water. The present study was approved by the Ethics Committee of The Affiliated Qingdao Hiser Hospital of Qingdao University (Qingdao, China).

Experimental reagents. The following materials and reagents were used in the present study: EGF solution (Wuhan Healthgen Biotechnology Corp., Wuhan, China); Sumianxin (Jilin Huamu Animal Health Product Co., Ltd., Changchun, China); alloxan monohydrate (Hefei Bomei Biotechnology Co., Ltd., Hefei, China); glucometer and blood glucose kit (Hua Xia Kangning Xuzhou Medical Technology Co., Ltd., Xuzhou, China); RNA PCR kit (AMV) Ver.3.0 (Takara Biotechnology Co., Ltd., Dalian, China); and the RNAprep Pure Tissue kit [cat. no. DP431; Tiangen Biotech (Beijing) Co., Ltd., Beijing, China].

Experimental equipment. The following equipment were used in the present study: NanoDrop ND-1000 Ultraviolet Spectrometry Photometer (Shanghai Spectrum Instruments, Co., Ltd., Shanghai, China); $\mathrm{CO}_{2}$ incubator (Shanghai SANTN Instruments Co., Ltd., Shanghai, China); a gel imaging system (UVP, Inc., Upland, CA, USA); a $-80^{\circ} \mathrm{C}$ freezer (Wuxi Guanya Refrigeration Technology Co., Ltd., Wuxi, China); an light microscope; a transmission electron microscope; Nucleic Acid and Protein Analyzer (Suzhou Qile Electron Technology Co., Ltd., Kunshan, China); and a gradient PCR instrument (Beijing Bohui Innovation Technology Co., Ltd., Beijing, China).

Induction of type II diabetes. New Zealand rabbits were fed with a high-fat/high-sucrose diet for 2 months prior to the induction of type II diabetes, as previously described $(25,26)$. Following this 2-month period, diabetes was induced by administering rabbits with $50 \mathrm{mg} / \mathrm{kg}$ body weight alloxan monohydrate $(2.5 \%)$ via the ear of each rabbit every 3 days following $6 \mathrm{~h}$ of fasting. On day 10, the rabbits were fasted overnight (8-10 h with water) prior to the collection of blood samples. The rabbits that exhibited a fasting blood glucose level $>11.1 \mathrm{mmol} / 1$ were admitted to the type II diabetes model. A total of 48 rabbits were included in the present study as 17 rabbits did not meet the experimental standard.

Experimentalgroups and therapeutic measures. The remaining 48 type II diabetes rabbits were randomly and equally divided into treatment and control groups. The legs of all rabbits were disinfected with $100 \mathrm{ml}$ iodophor solution (Shandong Lierkang Medical Technology Co., Ltd., Dezhou, China) and animals were anesthetized using $200 \mathrm{mg} / \mathrm{kg}$ Sumianxin administered to the hind leg, were muscle was abundant. A 10x10 mm section of full-thickness skin was excised, followed by a radial debridement of the wound. For the treatment group, $100 \mathrm{mg} / \mathrm{l}$ EGF solution was applied to the wound every day for 1 month; continuous contact between the EGF solution and wound was maintained as described previously (27). No treatment was administered to the control group. During the experiment, the feeding and sanitary conditions of the 2 groups were the same. A digital camera was used to capture images of the DFU wound, and record the wound healing rate and healing area in real time once every five days, using Masson and hematoxylin and eosin (HE) staining. The wound healing rate calculation formula was as follows: Wound healing rate = (original wound area - non healing area)/original wound area.

Histological analysis. Following 20 days of treatment, a 2-mm region of newly produced granulation tissue from the DFU site was collected from all rabbits in both groups. Prior to tissue collection, the rabbits were injected with $200 \mathrm{mg} / \mathrm{kg}$ body weight Sumianxin intramuscularly $(22,23)$. The collected samples were irrigated with distilled water and divided into four sections. These tissue sections were then used for Masson staining, HE staining, electron microscopy observation and reverse transcription-polymerase chain reaction (RT-PCR) analysis of EGF mRNA levels.

Masson staining. Healing and granulation tissue specimens were removed from the surface of the diabetic foot ulcer. The samples were fixed in $10 \%$ formaldehyde solution, embedding in paraffin and dewaxed (thickness, $6 \mu \mathrm{m}$ ) Staining was performed according to the manufacturer's protocol connective tissue Masson staining kit (Abcam, Cambridge, UK). Samples were incubated with Masson staining solution at $37^{\circ} \mathrm{C}$ for $5 \mathrm{~min}$. Following two washes with $0.2 \%$ acetic acid for $5 \mathrm{~min}$, the sections were stained with $1 \%$ aniline for $5 \mathrm{~min}$ at room temperature. Following two more washing steps with $0.2 \%$ acetic for $5 \mathrm{~min}$, section were dehydrated $10 \mathrm{sec}$ at room temperature with absolute alcohol and rendered transparent $5 \mathrm{~min}$ at room temperature using xylene. Sections were observed using a light microscope (magnification, $\mathrm{x} 400$ ).

HE staining. After 15 days, healing specimens were removed from the surface of the diabetic foot ulcer of the experimental group and fixed $\left(10 \mathrm{~min} ; 20^{\circ} \mathrm{C}\right)$ in $40 \mathrm{~g} / 1$ paraformaldehyde solution. Gradient ethanol dehydration $\left(35^{\circ} \mathrm{C}, 1.5 \mathrm{~h}\right)$ and xylene $\left(30 \mathrm{~min} ; 35^{\circ} \mathrm{C}\right)$ was used in the sample preparation prior to embedding the specimens in paraffin $\left(60 \mathrm{~min}, 56^{\circ} \mathrm{C}\right)$. The specimens were sliced into $5-\mu \mathrm{m}$-thick sections and xylene was used to dewax the samples $\left(37^{\circ} \mathrm{C}, 10 \mathrm{~min}\right)$. They were stained with $\mathrm{HE}$ for $5 \mathrm{~min} 35^{\circ} \mathrm{C}$. The growth of fibroblasts and blood vessels was observed using a light microscope (magnification, $\mathrm{x} 1,600)$.

Molecular level detection. Total RNA was extracted using TRIzol reagents (Invitrogen; Thermo Fisher Scientific, Inc., Inc., Waltham, MA, USA) from the granulation tissue samples. This was performed according to the manufacturer's instructions. The synthesis of cDNA was carried out using a reverse transcription kit (RevertAid First Strand cDNA Synthesis kit; 
Table I. Primer sequences used for reverse transcription-polymerase chain reaction analysis.

\begin{tabular}{lllc}
\hline Gene & Forward primer sequence (5'-3') & Reverse primer sequence (5'-3') & Size (bp) \\
\hline Epidermal growth factor & TTGCTGCTCTACCTCCACCAT & CTGCATTCACATTTGTTGTGC & 354 \\
$\beta$-actin & CAACACGCCGGCCATGTA & TCCATGCCCAGGAAGGAG & 429 \\
\hline
\end{tabular}

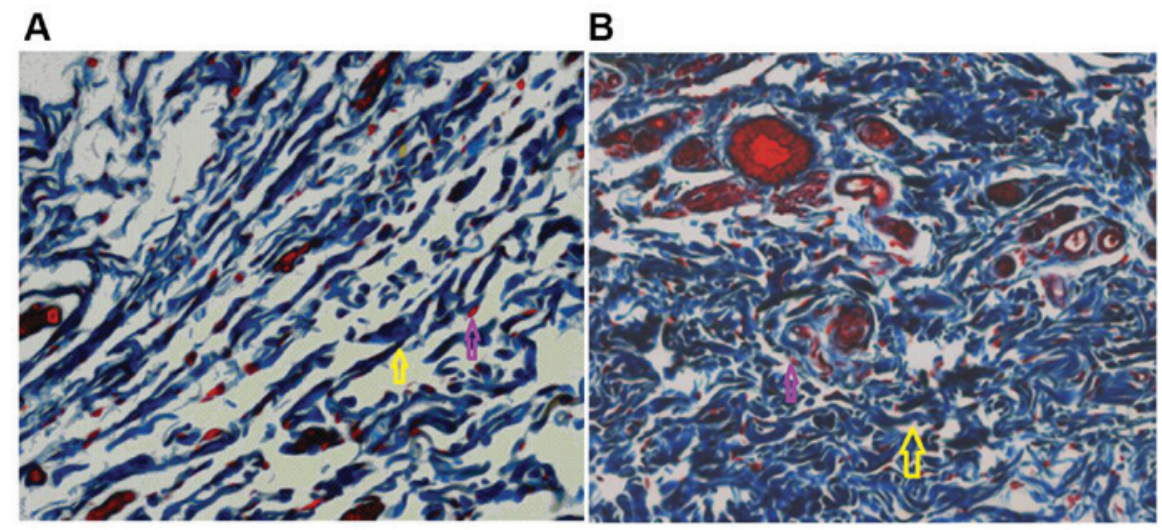

Figure 1. EGF increases granulation tissue production and the number of clustered fibroblasts. Masson staining was performed at 20 days following wound generation and treatment (A) with or (B) without EGF (magnification, x40). Yellow arrows highlight areas of clustered fibroblasts and the purple arrows highlight neutrophils. EGF, epidermal growth factor.

Fermentas; Thermo FisherScientific,Inc.). The reactionmixture was incubated at $37^{\circ} \mathrm{C}$ for $30 \mathrm{~min}$ followed by inactivated at $85^{\circ} \mathrm{C}$ for $5 \mathrm{~min}$. Polymerase chain reaction was performed with cDNA as template and the reaction volume was $20 \mu \mathrm{l}$. EGF mRNA expression was analyzed by semi-quantitative RT-PCR using the Qiaquick PCR kit (Qiagen, Inc., Valencia, CA, USA). The thermocycling conditions were as follows: $42^{\circ} \mathrm{C}$ for $30 \mathrm{~min}, 94^{\circ} \mathrm{C}$ for $5 \mathrm{~min}$, and 40 cycles of $94^{\circ} \mathrm{C}$ for $45 \mathrm{sec}$ and $60^{\circ} \mathrm{C}$ for $80 \mathrm{sec}$. $\beta$-actin was used as internal reference gene. Amplification products were analyzed using the following protocol: A total of $5 \mu \mathrm{l} /$ lane RT-PCR reaction mixture was separated by $2 \%$ agarose gel electrophoresis at a voltage of $80 \mathrm{~V}$. Samples were visualized using ethidium bromide. A gel imaging system was used to observe the gel and capture images, and the gray values were calculated using software (Shanghai Peiqing Science and Technology Co., Ltd., Shanghai, China). Densitometry analysis was performed using Bio1D (Vilber Lourmat, Marne la-Vallée, France). The primer sequences for EGF and $\beta$-actin are shown in Table I.

Capillary number. Fresh granulation tissue samples $(1.0 \times 1.0 \mathrm{~mm})$ were obtained from the wound surfaces of animals of the control and treatment groups. Samples were fixed for $10 \mathrm{~min}$ at $20^{\circ} \mathrm{C}$ with $20 \%$ formaldehyde, dehydrated at $35^{\circ} \mathrm{C}$ for $1.5 \mathrm{~h}$ and embedded in paraffin for $2 \min 22^{\circ} \mathrm{C}$. Continuous sections (thickness, $5 \mu \mathrm{m}$ ) were stained with $\mathrm{HE}$ solution as described. A light microscope was used to analyze the sections (magnification, x400). The number of capillaries with a complete lumen in each visual field was calculated and three visual fields per section were observed.

Statistical analysis. The data is presented as mean \pm standard deviation. Experiments were performed in duplicate. SPSS statistics software (version 19.0; IBM Corp., Armonk, NY, USA) was used for data analysis. A normal distribution detection and homogeneity of variance test were conducted prior to comparison tests among groups. Non-normal data were analyzed using Kruskal-Wallis test. $\mathrm{P}<0.05$ was used to indicate a statistically significant difference.

\section{Results}

EGF increases wound healing rates. The wound healing of rabbits in the EGF treatment group was faster than that of rabbits in the control group (Fig. 1). The mean time for the wound to become fully epithelized. In the experimental group, $78 \%$ of the animals were healed following 12 days of treatment, while in the control group $25 \%$ of animals exhibited wound closure following 25 days observation. The rabbits in the control group healed by day 25 and the healing rate was $35 \%$.

EGF increases granulation tissue production, neutrophil numbers, collagen uniformity and the extracellular matrix. The number of neutrophils in the experimental group was lower than that in the control group. Histological sections from the treatment and control groups were collected at 20 days following treatment. Granulation tissue production and the number of clustered fibroblasts were increased in the treatment group when compared with the control group (Fig. 1). The collagen bundles in the treatment group were dense and ordered, and the extracellular matrix was more abundant when compared with that of the control group (Fig. 2). In the control group, wound healing was relatively slow, histological structures were not evident and the collagen fibers were relatively sparse (Fig. 2). 
A

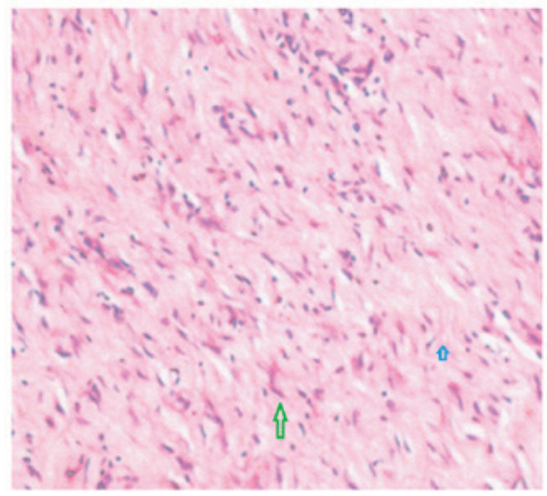

B

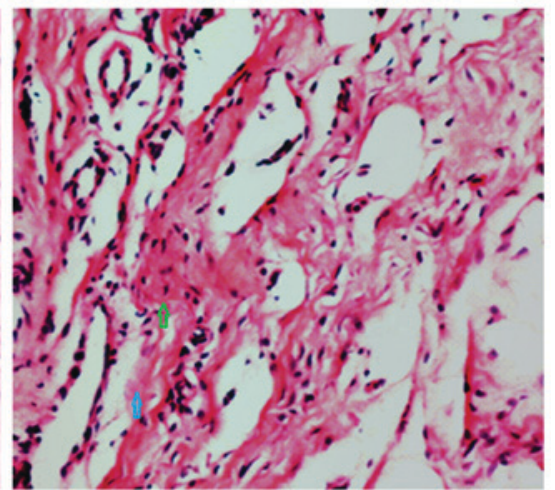

Figure 2. EGF increases the production of extracellular matrix and causes collagen structures to become dense and ordered. Hematoxylin and eosin staining was performed at 20 days following generation of the wound and treatment (A) with or (B) without EGF (magnification, x40). Blue arrows highlight the extracellular matrix and green arrows highlight collagen structures EGF, epidermal growth factor.

A

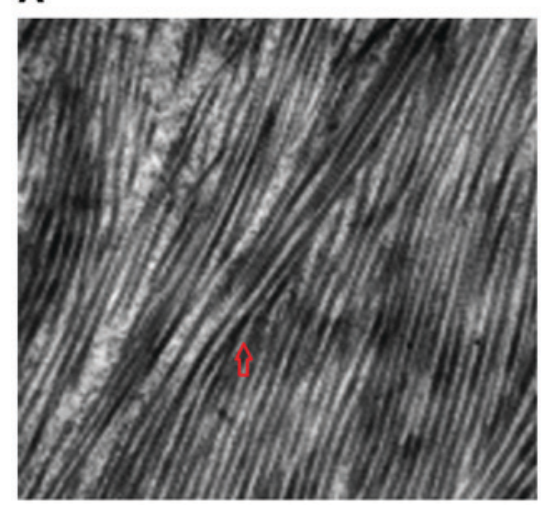

B

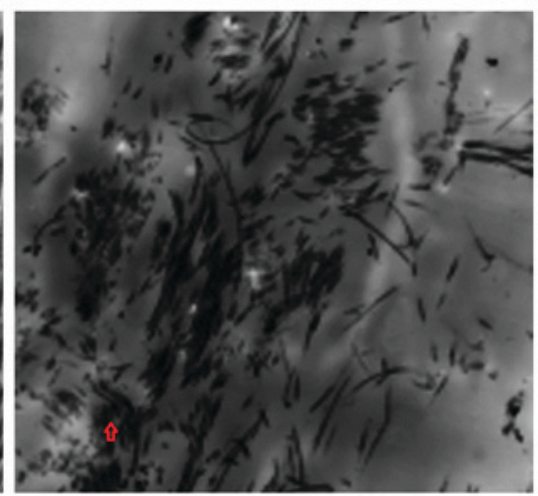

Figure 3. EGF increases the number of capillaries and fibroblasts, and improves the morphology of fibroblasts. Transmission electron microscopy was performed at 20 days following generation of the wound and treatment (A) with or (B) without EGF (magnification, x1,600). Red arrows highlight fibroblasts. EGF, epidermal growth factor.

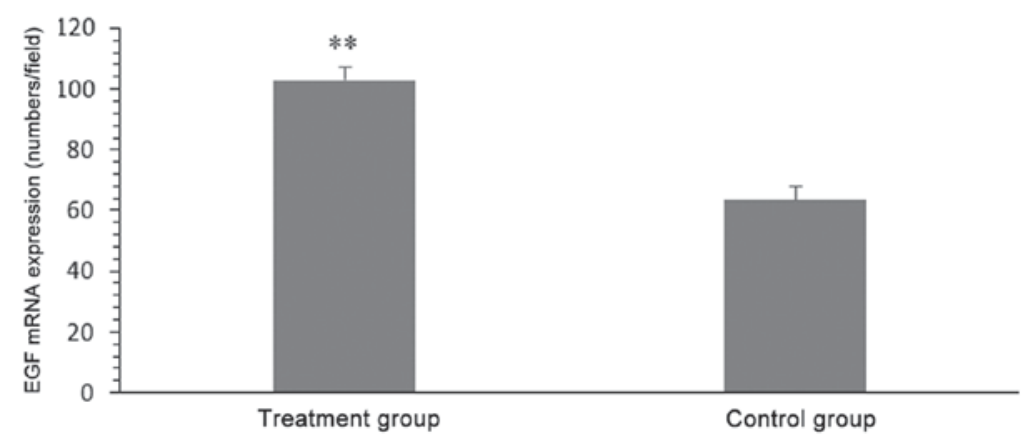

Figure 4. Epidermal growth factor mRNA expression in the treatment and control groups. ${ }^{* *} \mathrm{P}<0.01$

EGF increases the number of capillaries and fibroblasts, and improves fibroblast morphology. The number of fibroblasts and capillaries were increased in the treatment group compared with the control group (Fig. 3). The fibroblasts in the treatment group exhibited a uniform morphology and were abundant in organelles when compared with the fibroblasts in the control group.

Exogenous EGF treatment increases EGF mRNA expression. The relative gray value of EGF mRNA in the treatment group was higher than that of the control group was $(103.27 \pm 4.27$ vs. 63.88土4.36; $\mathrm{P}<0.05$; Fig. 4).

\section{Discussion}

When normal tissue is acutely injured, epithelial cells, fibrocytes and fibroblasts are damaged and the normal physiological process of wound healing is initiated (28). In DFU, the wound healing process is hindered by the accumulation of advanced glycation end products (AGEs), which is due to 
the high blood glucose levels of patients with diabetes $(29,30)$. AGEs competitively bind to the EGF receptor, thus preventing the binding of EGF and perpetuating the initial injury to the vascular endothelial cells and fibroblasts $(31,32)$. This leads to an increase in apoptosis of injured vascular endothelial cells and fibroblasts, and a decrease in cytokines and collagen production; collectively these phenomena decrease angiogenesis (33). The levels of inflammatory mediators also increase in the extracellular matrix of DFU lesions $(34,35)$. The wound healing process is inhibited by decreased neutrophil granulocyte numbers, inflammation, inflammatory cell chemotaxis and granulation tissue production (36). This type of wound takes a long time to heal and may never heal completely. However, topical treatments consisting of antibacterial nanoparticles (such as silver nanoparticle between 1 and $100 \mathrm{~nm}$ ) have been used against different pathogens, particularly Staphylococcus aureus and it was observed that these treatments can encourage wound healing $(37,38)$.

Previous studies have demonstrated that the degradation of growth factors, such as EGF, and their cell surface receptors are the main cause of refractory DFU wounds $(39,40)$. EGF was the first growth factor used to study wound healing $(41,42)$. A previous in vitro study demonstrated that EGF may promote mitosis and glycolysis (43). EGF receptors exist on the majority of cell surface membranes $(44,45)$. EGF induces the migration of inflammatory cells away from the wound, leading to an improvement of the wound microenvironment and the nutritional status of the tissue (46). Also, EGF can promote epidermal proliferation increasing fibroblast numbers in partial thickness wounds (47-49). Cellulose promotes cell proliferation and wound repair (50). The aforementioned studies support the results of the present study, which indicates that EGF may serve a positive role in the DFU wound healing process.

EGF is secreted by circulating platelets, macrophages and mononuclear cells (51). The results of the present study demonstrated that EGF mRNA expression in the group treated with exogenous EGF was higher than that of the control group. This may demonstrate that exogenous EGF promotes the expression of endogenous EGF, which upregulates partial EGF gene expression $(52,53)$. Experiments with single and multiple linear regression models should be designed and regression analyses performed to support the notion that exogenous EGF promotes endogenous EGF protein expression.

In conclusion, the results of the present study suggest that EGF binds to its corresponding receptor on epidermal cell and fibroblast cell surface membranes in order to build collagenous tissue, and accelerate the generation of wound granulation and epithelial tissues, which accelerate the wound healing process. The treatment of diabetic foot ulcer is long and expensive, and causes great pain to patients and families. Therefore, it is of great importance to find a novel treatment method DFUs. EGF demonstrated positive effects in promoting wound healing.

\section{Acknowledgements}

Not applicable.

\section{Funding}

Not applicable.

\section{Availability of data and materials}

The datasets used and/or analyzed during the current study are available from the corresponding author on reasonable request.

\section{Authors' contributions}

JZ and ZX designed the study. WH, QD and ZW were responsible for the collection and analysis of the data. JM and XC performed data analysis and interpretation. JZ and ZX prepared the manuscript. All authors read and approved the final manuscript.

\section{Ethics approval and consent to participate}

The present study was approved by the Ethics Committee of The Affiliated Qingdao Hiser Hospital of Qingdao University (Qingdao, China).

\section{Patient consent for publication}

Not applicable.

\section{Competing interests}

The authors declare that they have no competing interests.

\section{References}

1. Iraj B, Khorvash F, Ebneshahidi A and Askari G: Prevention of diabetic foot ulcer (DFU). Int J Prev Med 4: 373-376, 2013.

2. Wojciechowski VV, Calina D, Tsarouhas K, Pivnik AV, Sergievich AA, Kodintsev VV, Filatova EA, Ozcagli E, Docea AO, Arsene AL, et al: A guide to acquired vitamin K coagulophathy diagnosis and treatment: The Russian perspective. Daru 25: 10, 2017.

3. Asadi M, Alamdari DH, Rahimi HR, Aliakbarian M, Jangjoo A, Abdollahi A, Bahar MM, Azadmand A, Forghani N, Sadegh MN, et al: Treatment of life threatening wounds with a combination of allogenic platelet rich plasma, fibrin glue and collagen matrix, and a literature review. Exp Ther Med 8: 423-429, 2014.

4. Călina D, Docea AO, Rossu L, Zlatian O, Rossu AF, Anghelina F Rogoveanu O, Arsene AL, Nicolae AC, Drăgoi CM, et al: Antimicrobial resistance development following surgical site infections. Mol Med Rep 15: 681-688, 2017.

5. Tănase A, Colita A, Ianosi G, Neagoe D, Branisteanu DE, Calina D, Docea AO, Tsatsakis A and Ianosi SL: Rare case of disseminated fusariosis in a young patient with graft vs. host disease following an allogeneic transplant. Exp Ther Med 12: 2078-2082, 2016.

6. Blumberg SN, Berger A, Hwang L, Pastar I, Warren SM and Chen W: The role of stem cells in the treatment of diabetic foot ulcers. Diabetes Res Clin Pract 96: 1-9, 2012.

7. Mcardle C, Lagan K, Spence S and McDowell D: Diabetic foot ulcer wound fluid: The effects of $\mathrm{pH}$ on DFU bacteria and infection. J Foot Ankle Res 8 (Suppl 1): A8, 2015.

8. Buchberger B, Follmann M, Huppertz H and Wasem J: Health technology assessment (HTA) on the importance of growth factors for the treatment of diabetic foot ulcers (DFU). Das Gesundheitswesen 72: 491-501, 2010.

9. Sheehan P, Jones P, Caselli A, Giurini JM and Veves A: Percent change in wound area ofdiabetic foot ulcers over a 4-week period is a robust predictor of complete healing in a 12-week prospective trial. Diabetes Care 26: 1879-1882, 2003.

10. Gilligan AM, Waycaster CR and Landsman AL: Wound closure in patients with DFU: A cost-effectiveness analysis of two cellular/tissue-derived products. J Wound Care 24: 149-156, 2015.

11. Singh K, Singh VK, Agrawal NK, Gupta SK and Singh K: Association of toll-like receptor 4 polymorphisms with diabetic foot ulcers and application of artificial neural network in DFU risk assessment in type 2 diabetes patients. Biomed Res Int 2013: 318686, 2013. 
12. Mcdonnell J, Redekop K, Verboom P, Lovas K and Kalo Z: PDG15: The cost of treating diabetic foot ulcers (dfu) with apligraf in the Netherlands. Value Health 4: 508, 2001.

13. Hong JP, Jung HD and Kim YW: Recombinant human epiderma growth factor (EGF) to enhance healing for diabetic foot ulcers. Ann Plast Surg 56: 394-398; discussion 399-400, 2006.

14. Robson MC: Invited discussion: Recombinant human epidermal growth factor (EGF) to enhance healing for diabetic foot ulcers. Ann Plast Surg 56: 399-400, 2006.

15. Choi JS, Leong KW and Yoo HS: In vivo wound healing of diabetic ulcers using electrospun nanofibers immobilized with human epidermal growth factor (EGF). Biomaterials 29: 587-596, 2008.

16. Mohan VK: Recombinant human epidermal growth factor (REGEN-D 150): Effect on healing of diabetic foot ulcers Diabetes Res Clin Pract 78: 405-411, 2007.

17. Aktaş Ş, Baktıroğlu S, Demir L, Kılıçoğlu Ö, Topalan M, Güven E, Mirasoğlu B and Yanar F: Intralesional application of epidermal growth factor in limb-threatening ischemic diabetic foot ulcers. Acta Orthop Traumatol Turc 50: 277-283, 2016.

18. Dumantepe M, Fazliogullari O, Seren M, Uyar I and Basar F: Efficacy of intralesional recombinant human epidermal growth factor in chronic diabetic foot ulcers. Growth Factors 33: 128-132, 2015.

19. Chen F, Lin L, Zhang HJ, Ye XX, Zhao WZ, Wang T and Yang $\mathrm{XN}$ : Roles of hepatocyte growth factor, c-Met and epidermal growth factor receptor in repair of colonic mucosa from patients with ulcerative colitis. Shiji Hua Ren Xiao Hua Za Zhi 14 594-599, 2006 (In Chinese).

20. Chen F, Lin L, Zhang HJ and Wang T: Effect of epidermal growth factor receptor in the repair of colonic mucosa in patients with ulcerative colitis. Zhongguo Lin Chuang Kang Fu Za Zhi 9: 104-106, 2005 (In Chinese).

21. Sun L, Kwok E, Gopaluni B and Vahidi O: Pharmacokineticpharmacodynamic modeling of metformin for the treatment of type II diabetes mellitus. Open Biomed Eng J 5: 1-7, 2011.

22. Hu YH, Yun SF, Zhou SM and Tian XY: Influence of Sumianxin Anesthesia on Physiology in Rabbits. Zhongguo Bi Jiao Yi Xue Za Zhi 16: 475-478, 2006 (In Chinese).

23. Cao CY, Kang N, Yan L, Hu ZY, Shen ZH and Wang Q:Anesthetic effect of sumianxin II combined with chloral hydrate on rabbit. Zhongguo Bi Jiao Yi Xue Za Zhi 24: 25-18, 2014 (In Chinese).

24. Huang J: Scientific breeding management of experimental rabbits. Animal Husbandry Veterinarian of Zhejiang 3: 47, 1995.

25. Li X, Liu W, Kou H, Zhou W, Li T, Dong B and Liang P: Experimental study of image-guided percutaneous microwave ablation in rabbit lung VX2 tumor model. Int J Clin Exp Pathol 7 : 905-913, 2014

26. Yuan ZW, Pei LY, Qiu JL, et al: Anesthesia of commonly used experimental animals. Chinese J Comparative Medicine 14 245-247, 2004 (In Chinese).

27. Pixin R and Shengfu D: Effects of epidermal growth factor (EGF) on circumflex function of isolated pulmonary artery in rats. Chinese J Pathophysiol 2: 173-176, 1994 (In Chinese).

28. Liu Y, Pei G and Jiang S: New porous beta-tricalcium phosphate as scaffold for bone tissue engineering. Zhongguo Xiu Fu Chong Jian Wai Ke Za Zhi 21: 1123-1127, 2007 (In Chinese).

29. Ertugrul BM, Buke C, Ersoy OS, Ay B, Demirez DS and Savk O: Intralesional epidermal growth factor for diabetic foot wounds: The first cases in Turkey. Diabetic Foot Ankle 6: 28419, 2015.

30. Fan HJ, Yu JH, Cui GM, Zhang WY, Yang X and Dong QJ: Insulin pump for the treatment of diabetes in combination with ulcerative foot infections. J Biol Regul Homeost Agents 30 : 465-470, 2016.

31. Thomson SE, McLennan SV and Twigg SM: Growth factors in diabetic complications. Expet Rev Clin Immunol 2: 403-418, 2006.

32. Han HM, Guo L, Jiang LJ, Jiang XY, Lv YL, Pang JK, Bai ZM, Che WJ, Xu RH, Yu P and Li Q: A microarray study on the molecular mechanism for the therapeutic effect of Antidotal and Myogenic Ointment on the foot ulcer in diabetic rats. Zhongguo Wei Zhong Bing Ji Jiu Yi Xue 23: 621-624, 2011 (In Chinese)

33. Wan Y, Yang YJ, Li YS, Li XJ, Zhang W, Liu M and Tang HB Effects of San-huang-sheng-fu oil on peripheral circulatory disorders and foot ulcers in diabetic rats and the mechanisms. Zhonghua Shao Shang Za Zhi 32: 168-175, 2016 (In Chinese).

34. Demidova-Rice TN, Hamblin MR and Herman IM: Acute and impaired wound healing: Pathophysiology and current methods for drug delivery, part 2: Role of growth factors in normal and pathological wound healing: Therapeutic potential and methods of delivery. Adv Skin Wound Care 25: 349-370, 2012.
35. Jennings JA, Crews RM, Robinson J, Richelsoph K, Cole JA, Bumgardner JD, Yang Y and Haggard WO: Effect of growth factors in combination with injectable silicone resin particles on the biological activity of dermal fibroblasts: A preliminary in vitro, study. J Biomed Mater Res B Appl Biomater 92: 255-260, 2010.

36. Yuan N, Wang C, Wang Y, Yu T, Long Y, Zhang X and Ran X: Preparation of autologous platelet-rich gel for diabetic refractory dermal ulcer and growth factors analysis from it. Zhongguo Xiu Fu Chong Jian Wai Ke Za Zhi 22: 468-471, 2008 (In Chinese).

37. Zhou LS, Liao ZJ, Zhang Q, Luo M, Lu G and Zhang W: Bio-inductive effects of inorganic elements on skin wound healing. Zhonghua Shao Shang Za Zhi 21: 363-366, 2005 (In Chinese).

38. Jiang XH, Zhou WM, He YZ, Wang Y, Lv B and Wang XM: Effects of lipopeptide carboxymethyl chitosan nanoparticles on Staphylococcus aureus biofilm. J Biol Regul Homeost Agents 31: 737-743, 2017.

39. Buteică AS, Mihăescu DE, Grumezescu AM, Vasile BS, Popescu A, Călina D and Mihăiescu OM: The citotoxicity of (non)magnetic nanoparticles tested on Escherichia coli and Staphylococcus aureus. Dig J Nanomater Biostruct 5: 651-655, 2010.

40. Acosta JB, Savigne W, Valdez C, Franco N, Alba JS del Rio A, López-Saura P, Guillén G, Lopez E, Herrera L and Férnandez-Montequín J: Epidermal growth factor intralesional infiltrations can prevent amputation in patients with advanced diabetic foot wounds. Int Wound J 3: 232-239, 2006.

41. Galkowska H, Wojewodzka U and Olszewski WL: Chemokines, cytokines, and growth factors in keratinocytes and dermal endothelial cells in the margin of chronic diabetic foot ulcers. Wound Repair Regen 14: 558-565, 2006.

42. Pedro A López Saura, Jorge Berlanga Acosta, José I, Fernández Montequín, Carmen Valenzuelá Silva, Odalys González Díaz, William Savigne, Lourdes Morejoń Vega, Amauryś del Río Martín, Luis Herrera Martínez, et al: Intralesional human recombinant epidermal growth factor for the treatment of advanced diabetic foot ulcer: From proof of concept to confirmation of the efficacy and safety of the procedure. Zhur. Eksptl'. i Teoret. Fiz. 21: 406-409, 2011

43. Bennett SP, Griffiths GD, Schor AM, Leese GP and Schor SL: Growth factors in the treatment of diabetic foot ulcers. Br J Surg 90: 133-146, 2003.

44. Margolis DJ, Bartus C, Hoffstad O, Malay S and Berlin JA: Effectiveness of recombinant human platelet-derived growth factor for the treatment of diabetic neuropathic foot ulcers. Wound Repair Regen 13: 531-536, 2005 .

45. Buchberger B, Follmann M, Freyer D, Huppertz H, Ehm A and Wasem J: The evidence for the use of growth factors and active skin substitutes for the treatment of non-infected diabetic foot ulcers (DFU): A health technology assessment (HTA). Exp Clin Endocrinol Diabetes 119: 472-479, 2011.

46. Galstyan GR, Ignatieva VI, Avksentieva MV and Dedov II: Pharmacoeconomic analysis of epidermal growth factor $\left(\right.$ Heberprot $\left.\mathrm{P}^{\circledR}\right)$ for the treatment of diabetic foot ulcers. Endocrine Surgery 7: 4-15, 2013.

47. Tuyet HL, Nguyen Quynh TT, Vo Hoang Minh H, Thi Bich DN, Do Dinh T, Le Tan D, Van HL, Le Huy T, Doan Huu H and Tran Trong TN: The efficacy and safety of epidermal growth factor in treatment of diabetic foot ulcers: The preliminary results. Int Wound J 6: 159-166, 2009.

48. Tiaka EK, Papanas N, Manolakis AC and Georgiadis GS: Epidermal growth factor in the treatment of diabetic foot ulcers: An update. Perspect Vasc Surg Endovasc Ther 24: 37-44, 2012.

49. Afshari M, Larijani B, Fadayee M, Farzaneh Darvishzadeh, Ghahary A, Pajouhi M, Bastanhagh MH, Baradar-Jalili R and Vassigh AR: Efficacy of topical epidermal growth factor in healing diabetic foot ulcers. Therapy 2: 759-765, 2016.

50. Lihuan D: Regenerated cellulose skin repair materials: preparation and performance. Zhongguo Zu Zhi Gong Cheng Yan Jiu 19: 6098-6103, 2015 (In Chinese).

51. Singla S, Singla S, Kumar A and Singla M: Role of epidermal growth factor in healing of diabetic foot ulcers. Indian J Surg 74: 451-455, 2012.

52. Gałkowska $\mathrm{H}$ and Olszewski W: Cellular and molecular basis of impaired healing of diabetic foot ulcers. Polish J Surg 79: 720-727, 2007.

53. Li Q, Wang Y and Yang L: Curative effect observation of recombinant human epidermal growth factor in treatment of oral ulcer in children with hand-foot-mouth disease. Erke Yao Xue Za Zhi 23: 533-547, 2015 (In Chinese).

This work is licensed under a Creative Commons

Attribution 4.0 International (CC BY 4.0) License. 